\title{
Redressing Small Firm Resilience: Exploring Owner-Manager Resources for Resilience
}

\begin{abstract}
Purpose: The owner-manager of small firms is recognised as having a potentially significant role in the small firm's competitiveness, growth and failure. However, the owner-manager's own resilience has been largely overlooked in the small firm resilience literature. The purpose of this paper is to redress this and expand the debate and empirical basis of small firm owner-managers' personal resources for resilience.

Design/methodology/approach: This longitudinal qualitative study deployed semi-structured interviews with nine owner-managers, each being interviewed three or four times. Analytical procedures were employed utilising an established framework which conceptualised four key personal resources for resilience as adaptability, confidence, social support, and purposefulness.

Findings: There were four key findings: (1) owner-manager adaptability can appear in extremes including a sense of helplessness or optimism where disruptive circumstances are not sensed as problematic, (2) owner-manager confidence levels often echoe their own mindset of adaptability, that is, from helplessness to positive ambition, (3) owner-managers can utilise discursive tactics with strong/weak ties for a range of affective as well as technical resources for resilience, and (4) purposefulness tended to be framed in terms of a necessity for a longer term future state related to own or family lifestyle, rather than profit. It is also noted that the owner-manager and the firm are closely interrelated and therefore enhancement of personal resilience resources is likely to positively influence their resilience, and therefore the resilience of the organisation and strategic capability of the firm.
\end{abstract}

Originality/value: The small firm resilience literature typically focuses on the organisational level which de-emphasises the salient role of the owner-manager and their resilience. This study attempts to redress this. 


\section{Introduction}

The significance of small firms to economies has been debated for some time, especially in relation to business continuity, growth, and failure (Storey, 1994; Morris et al 2015). Within this debate, there is increasing interest in relation to small firm resilience, broadly pertaining to capacities to positively 'bounce back' or adapt to disruptive circumstances (Korber and McNaughton, 2017). However, the extant literature tends to conceptualise small firm resilience at the organisational level (Thomas et al 2015) and although it acknowledges a role of the 'characteristics' of owner-managers, these are narrowly defined in terms of their skills and education (Gunasekaran et al, 2011). As such, the extant literature tends to de-emphasise the role of the owner-manager's personal resilience and the emerging evidence of the positive connection between individual resilience and business success (Fisher et al, 2016).

It is argued that such a de-emphasis is problematic because it underestimates the significant role of the owner-manager in small firms, who are oftentimes responsible for strategy development and realisation at a tactical, daily level, a symptom of small firms being comparatively dependent on key resources for day-to-day operations (Storey, 1994; SullivanTaylor and Branicki, 2011). As such, the personal capacities of owner-managers can have a direct and significant role in the strategic direction and operation of an organisation, especially in relation to when there are circumstances which are disruptive to business operations. As such, the capacities of the small firm to 'bounce back' or adapt to disruptions - an aspect of business success - is intimately entangled with the owner-manager's own personal resilience.

Yet the owner-manager's capacities to deal with such challenges or set backs are largely ignored in the literature, and are narrowly defined as a set of experiences, education, or traits (Gunasekaran et al, 2011). In contrast, a manager's ability to respond with resilience has been theorised as a combination of relationships, individual differences and capabilities, as well as situational factors, and described as personal resources for resilience (Cooper et al, 2013; Robertson, 2017). Given the critical and salient role of the owner-manager within the small firm context, and a dearth of conceptual and empirical work in this area, it is therefore important to further explore the personal resources of resilience. The purpose of this paper is to redress this area, i.e. to explore the nature and dynamics of the personal resources of resilience for small-firm owner-managers within the rich context of their operations.

This paper is structured as follows. The next section discusses the literature pertaining to small firm resilience, and argues that although there is increasing recognition that resilience is context sensitive and dependent, little is known about the context of the small firm ownermanagers. Following this, the methodology and methodological apparatus is outlined.

Specifically, a longitudinal approach was adopted, where interviews were undertaken with nine owner-managers at various points over time. Next, data relating to the owner-managers' personal resources for resilience are presented in relation to four key areas as an established framework for analytical exploration: adaptability, confidence, social support, and purposefulness (see Cooper et al, 2013). These findings are then juxtaposed to the extant literature to develop and elucidate contributions in relation to the themes of this study. Finally, implications and future directions are outlined to build more nuanced understandings of the links between the personal resilience of small firm owner-managers and the small firm. 


\section{(Owner-)managers' personal resources for resilience}

The conceptualisation of resilience has emerged as a complex and multidisciplinary phenomenon linked to coping, learning, and adapting to adverse or extreme events (Fletcher and Sarkar, 2013), and has been theorised as a trait, cluster of processes, outcomes, or a combination of these (Hu et al, 2015; Estrada et al, 2016). Similarly, it has been conceptualised at different levels of analysis including individual, team, organisational, and community (Kent et al, 2014; King, 2016), some of which are problematized within the context of owner-managers in small firms given their centrality within the team-organisation (Osiyevskyy and Dewald, 2015; Wall, 2017).

Additionally, empirical work has also acknowledged diversity in how resilience manifests across different contexts and occupational settings, reflecting not just individual differences, but also situational and cultural dimensions (Ungar, 2011; Ungar and Liebenberg, 2011; Kossek and Perrigino, 2016; Linnenluecke, 2017).

Within the context of small firms, resilience has tended to be conceptualised and examined at the organisational level (Thomas et al 2015; Bernard and Barbosa 2016; Korber and McNaughton, 2017). Gunasekaran et al, (2011), for example, theorise the ways in which internal factors support resilience and highlight the role of organisational structure and managerial characteristics, external factors such as globalisation, and enabling factors such as how technology and supply chain integration interact to generate competitiveness (also see Ismail et al, 2011; Demer et al 2011; Ates and Bititci, 2011; Ali et al 2017). Within this conceptualisation, the owner-manager's 'characteristics' are limited to multi-tasking abilities, managerial skill, and training and education (Gunasekaran et al, 2011). Similarly, the entrepreneurial literature demonstrates a de-contextualisation and de-personalisation of factors pertinent to resources for resilience (Bernard and Barbosa, 2016; Korber and McNaughton, 2017). As such, both of these facets decouple the understanding of 'the person' within the context of their relationships and their impact upon personal resilience, as intertwined with the organisationally related interactions and their related personal networks.

Specifically, within the small firm context, the resilience of the owner-manager is potentially exposed to particular situational circumstances such as work overload, personal responsibility for others, and is located as a key driving-factor in strategy development and realisation processes (Ismail et al, 2011; Osiyevskyy and Dewald, 2015; Baron et al 2016), remains relatively unexplored. Small firms have unique characteristics in terms of lacking in resourcefulness, technical capability, organisational configuration, and rapidity (Sullivan-Taylor and Branicki, 2011), which are all linkable directly to the owner-manager. Similarly, emerging evidence of a positive relationship between individual resilience and business success is empirically supported (Fisher et al, 2016). As such, the collective literature provides compelling evidence to further explore small firm resilience with a specific focus on the individual ownermanager as a primary contributory component. A framework is now outlined as follows to facilitate this.

Examining the resilience of managers, Cooper et al (2013) conceptualise a framework describing managers' personal resources for resilience, which synthesises empirical work into relationships, individual differences and capabilities, situational factors, and how these interact to generate resilience outcomes (Robertson, 2017). Here, resilience is conceptualised as the ability of the individual to "bounce back from setbacks and to keep going in the face of tough demands and difficult circumstances" (Cooper et al, 2013: p15), and the resources are conceptualised as four clusters which shape 'bounce back' outcomes: adaptability, purposefulness, confidence, and social support. As such, these resources for resilience shape how managers sense their internal and external environments, how they respond to it in practice, and then, in turn, how the situational environment responds. Over time, therefore, the personal resources for resilience have a mutually constitutive relationship in practice. Given the prior establishment and empirical recognition of this framework to examine the resilience resources of managers, it has been 
adopted as a suitable analytical device to frame and structure data analysis. Each of the aspects of this framework are now discussed.

Adaptability. This cluster of personal resources relates to intelligence, problem solving capabilities, and abilities to improvise, in order for the manager to flex their action or approach to generate new ideas or courses of action in challenging circumstances (Cooper et al, 2013). In the context of small firms, earlier research highlighted that problem solving and the mobilisation of resources to resolve problems or address disruptions were a barrier to resilience in small firms, although there was the potential for agile and rapid responses (Sullivan-Taylor and Branicki, 2011). More recently, Osiyevskyy and Dewald (2015) found that cognitive factors such as framing in problem solving could lead to fundamental changes in business models, particularly in relation to responding to new business opportunities. The extent to which an owner-manager is able to adapt may therefore be influenced by their own creative capacities in addition to resource availability. In turn, this leads to:

\section{Proposition 1: Owner-manager adaptability (flexibility in framing and solving problems)} is positively associated to experiences of small firm resilience.

Purposefulness. This cluster of personal resources relates to conscientiousness and selfcontrol in relation to a sense of purpose, values, and meaning which guide sense making and action taking in challenging circumstances (Cooper et al, 2013). In a similar way to deciding how to mobilise limited resources to adapt to new situations, the prioritisation of responses in relation to a wider strategic perspective or purpose has been identified as an issue for small firms (Sullivan-Taylor and Branicki, 2011). Here, 'muddling through' or resistance to action taking was reported as being a barrier to small firm resilience (ibid). Indeed, Berkelaar and Buzzanell (2015) have explored the importance of purposefulness and meaning in work in organisations, including in relation to sense making. They found broad categories of purposefulness relation to necessity, agency, or inequality, but also identified that each could have mobilising and demobilising effects in practice (ibid).

Proposition 2: Owner-manager sense of purposefulness (longer term goals as guides for sense-making) is positively associated to experiences of small firm resilience.

Confidence. This cluster of personal resources relates to positive emotion and self-belief in being able to change circumstances for the better, when experiencing challenging circumstances (Cooper et al, 2013; Kay 2016). Such confidence involves self-regulatory mechanisms which control "emotions, thoughts, and behaviors..." and are "...critical to facilitating an individual's efforts to experience less turmoil, make sense of troubling events, and gain self-efficacy to move forward" (Rothstein et al, 2016: 418). Within the context of nascent small firm owner-managers, this sense of control, however, was identified as being both efficacious as well as misplaced which may have dramatic consequences on the small firm (Hayek, 2012). Indeed, Baron et al (2016) found that those setting up new small firms experience comparatively lower levels of stress from higher levels of self-efficacy, optimism, and hope. In this way, confidence, as built through 'small victories' which build self-esteem and efficacy over time (Bernard and Barbosa, 2016), can have a protective as well as mobilising function when dealing with disruptions (Quoidbach et al 2015; Wall et al 2017c).

\section{Proposition 3: Owner-manager sense of confidence (positive emotion and self-belief) is positively associated to experiences of small firm resilience.}

Social support. This cluster of personal resources relates to sociability, self-awareness, and the awareness of others, culminating in a mutually supportive network of relationships which is drawn upon when needed in challenging circumstances (Cooper et al, 2013). Earlier research 
highlighted that managers in small firms experienced an "overall emphasis on supply and infrastructure and the role of interorgansational dependence", which overshadowed the need and concern for the development of technical management capabilities (Sullivan-Taylor and Branicki, 2011: 5570). Similarly, other studies have highlighted the functional role of strong and weak social networks, under a variety of competitive through to cooperative environments, in responding to business disruptions (Chiesi, 2014; Yilmaz Borekci et al, 2015; Yang and Danes 2015). As such, social support may have a protective as well as mobilising function when dealing with disruptions in a small business context (Bernard and Barbosa, 2016; Wall, 2016).

\section{Proposition 4: Owner-manager social support (social network resources) is positively associated to experiences of small firm resilience.}

Given the symbiotic links between owner-manager and organisation for success and the lack of prior empirical work which considers them in their specific context, the resulting research question is what is the experience of small firm owner-managers in terms of their resources for resilience? The framework outlined and discussed above is adopted to help explore the experiences of small firm owner-managers, i.e. in terms of adaptability, purposefulness, confidence and social support framework (Cooper et al, 2013). This is summarised below.

\begin{tabular}{|c|c|}
\hline $\begin{array}{l}\text { Proposition 1: Owner-manager adaptability } \\
\text { (flexibility in framing and solving problems) } \\
\text { is positively associated to experiences of } \\
\text { small firm resilience. }\end{array}$ & $\begin{array}{l}\text { Proposition 2: Owner-manager sense of } \\
\text { purposefulness (longer term goals as guides } \\
\text { for sense-making) is positively associated to } \\
\text { experiences of small firm resilience. }\end{array}$ \\
\hline $\begin{array}{l}\text { Proposition 3: Owner-manager sense of } \\
\text { confidence (positive emotion and self belief) is } \\
\text { positively associated to experiences of small } \\
\text { firm resilience. }\end{array}$ & $\begin{array}{l}\text { Proposition 4: Owner-1 } \\
\text { (social network resourc } \\
\text { associated to experienc } \\
\text { resilience. }\end{array}$ \\
\hline
\end{tabular}

Table 1. Summary of propositions (informed by Cooper et al 2013).

\section{Methodology}

This exploratory study was conducted through a critical theorist paradigm (Schwandt, 1997, Johnson and Duberley, 2000). Here, this metaphysical stance assumes there is a reality but that it cannot be captured directly, but can be reported or documented by the actors who are immersed within a rich and complex context and interpreted. Within this approach, abductive reasoning seeks to provide insight through anchoring it to personal 'realities' reported through examination and consideration of respondent views and contextual case information. Methodologically, such an in-depth qualitative approach allows an immersive understanding and access to a depth of insight unachievable by other feasible "outsider" means and which determines the methods used.

The study utilised semi-structured interviews with small firm owner-managers (specifically those owner-managers who has were involved in strategy formulation, development, and realisation processes). Nine respondents, one per organisation, were each interviewed three or four times over the course of the study (see appendix 1 for a summary of the organisations participating in this study). This longitudinal approach allowed changes in the company and in the position and perspectives of the respondents to be recorded, hence gaining a greater insight to the context and development of the issues noted. Additionally, repetitive contact with the respondents allowed the establishment of rapport and trust between the researcher and the respondent and therefore encouraged a deeper disclosure of potentially sensitive matters (Yin, 2003, p.46). The organisations were selected through a purposive sampling approach, with differing characteristics and contexts to add to rich insights to the field (Denzin and Lincoln, 2000, p.370). 
In order to gain a greater insight to the context of each organisation then secondary data was gathered to form a mini-case for each organisation, which allowed the researcher to both understand any impacts occurring upon the firm and to ensure that they could relate and respond to occurrences around the firm. This further enhanced the ability of the researcher to engage the respondent in a meaningful exchange and explore the points being made with greater depth. This data included company reports, website information and sectoral reports. Each of the interviews was between 45 and 60 minutes long and transcribed to enable data analysis to be carried out through the use of NViVO. Great care was taken during transcription to ensure that the punctuation was appropriately inserted, helping the meaning of the response to be more clearly captured during the analysis. Where any queries arose in this respect the original recordings were used to clarify and confirm meaning.

In terms of analytical procedures, a priori code of 'learning' was applied in relation to the small firm strategy formulation, development, and realisation processes (Mintzberg et al 1998). Within this broader analysis, resilience was identified as an emergent theme in the data generated with the study participants, in terms of their personal performance and well-being, the operation, direction and success of the organisation, and the inter-connectedness of these. Within the broader theme of resilience the four resources for resilience articulated from the literature became sub-codes to help elucidate analyses in the areas of adaptability, purposefulness, confidence and social support. As such, the sub-codes were applied as an analytical device to frame the interpretation of the data pertaining to the phenomenon under study from the detailed field work. Specifically, particular empirical occurrences of data from each respondent were identified and analysed in relation to each of the sub codes (transcripts amounting to circa 100,000 words).

Consistent with the methodological approach taken, it is noted that whilst the findings of this study may be considered as reflective of the experiences for these owner-managers of small firms, they are not intended to be generalisable to the wider small firm owner-manager population. Instead, this study is primarily designed to explore the theoretical boundaries of existing by elucidating a more nuanced understanding of resilience in the context of small firm owner-managers, to prompt further theoretical consideration and refinement. The result of the analytical procedures is now presented in the findings section below.

\section{Findings}

The findings are outlined in relation to the owner-manager's resources for resilience: adaptability, purposefulness, confidence, and social support (informed by Cooper et al 2013). As noted these are sub codes derived from the literature and formed the conceptual framework as depicted in Figure 1 below. Data is selected, from the extensive and rich data generated by the in-depth qualitative approach taken, in relation to each of resources for resilience, and illustrative data are selected and presented to elucidate and exemplify the analytical points being articulated. This data includes participant statements as well as contextual information about the individual and their organisational and wider business environment. 


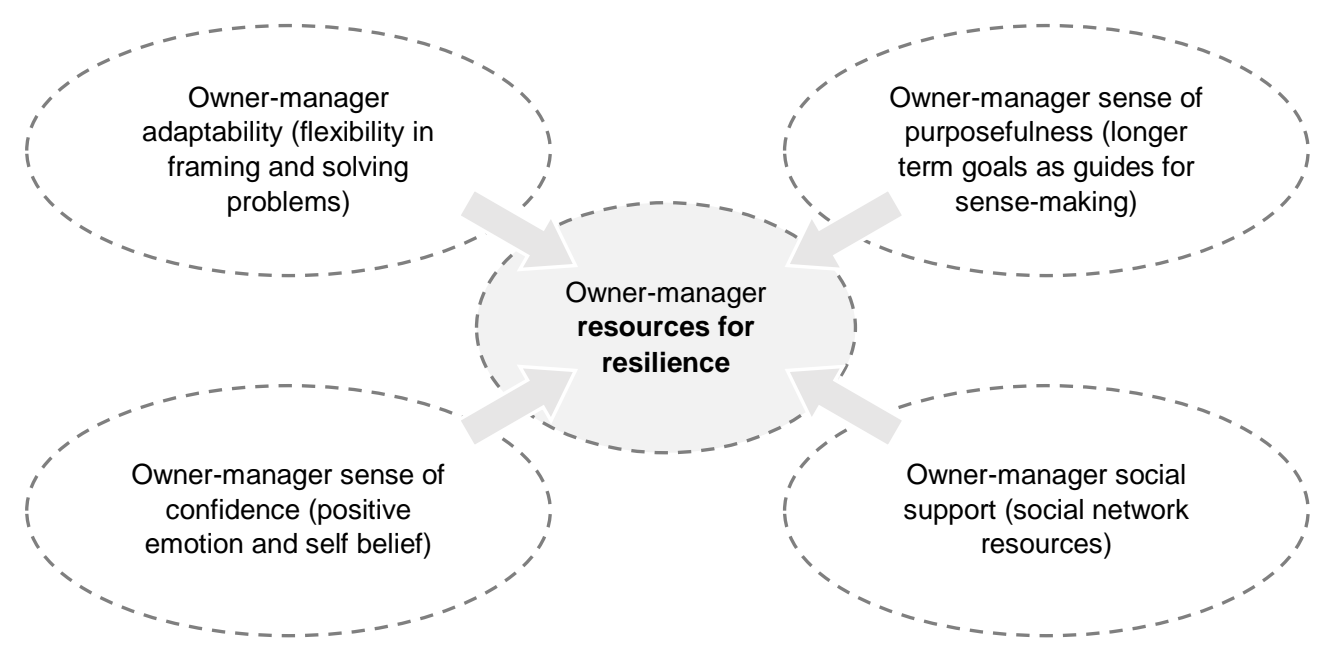

Figure 1. Analytical framework (informed by Cooper et al 2013).

\section{Owner-manager adaptability}

Evidence of adaptability varied across the group. Some of the respondents showed an openness to moving the business in differing directions and others appeared to be more constrained. For example, small firm C5 illustrated an inability to adapt their business approach, despite discussing, but apparently dismissing, options with the researcher previously. Within this small firm, an owner-manager explained how this was proving to be a cause of stress within their context:

"I didn't have any control over the situation and I racked my brain, there was nothing I could do despite how hard I tried and it doesn't matter how hard you work... if you haven't got control of anything, if you haven't got control over people buying from you there's not a damned thing you can do about it."

Here, and as expressed over longitudinal data, there is a sense that the owner-manager recognised the need to intentionally manage the challenges of the portfolio to cope with aspects such as seasonality and variable economic activity. However, they did not express such adaptability within their actual decision making and action taking even when different strategic alternatives were known to be available. Given that the owner-manager displayed an awareness in this respect, yet still responded in ways which demonstrated a lack of control, indicates a form of self-imposed limitation in how they construct and respond to their context. Similarly, over time, there was limited reflection around potential and alternative options for action which seemingly restricted the potentiality of acting differently as the owner-manager. This finding concurs with the works of Sullivan-Taylor and Branicki (2011) around the need to promote more open thinking around strategic direction. The inability to respond within the situation also indicated the possible interrelationships with other resources for resilience such as confidence (e.g. in expressing a sense of certainty in decision making or action taking), purposefulness (e.g. in setting or changing a direction for the firm), and the support seeking behaviours through social networks.

Such experiences and dynamics were shared across the participants in the study. For example, the feeling of helplessness was not isolated and an owner-manager in small firm C8 similarly illustrated a position where they too felt that they were not able to take alternative routes, though again options were, arguably available to them: 
"...in the last five years more difficult to plan for any longer than a couple of months in front of you because economically there's been so many things that have been... outside the business that are totally out of your control... that have been global, that have been national... no matter how much you look at things you wouldn't have known would impact on the business like this... it's like being in a boat in the middle of, the ocean and waiting for the wind to hit you."

Here, the reference to planning indicated a mind-set more reflective of a prescriptive approach rather than an emergent approach in meeting the challenges of a changing sector, which stands counter to the evidence which supports the distinctive responsiveness of small firms. However, these potentially self-imposed restrictions were not universal and an owner-manager in small firm C7 indicated their ability to deal with challenges in a responsive and adaptable way:

"I think we've just got to see how the opportunities begin to show themselves, but remain agile, not stuck in one particular route or another ... you only have to navigate at sea to find yourself sometimes very surprised by a lighthouse... because there are tides and there are currents there. And I think navigation at all times must be to say "where are we, where are we going' and I think it's part of that constant recheck."

A further illustration of the efficacy of this is where one small firm manager displayed an altogether more entrepreneurial approach than others and illuminated how they were frustrated by their current progress but able to see alternative ways forward:

“And we've got a meeting later today... to decide whether that's something we do or not. And my view is that we will do that... if we want our business to grow... we've got an opportunity to buy this company then I think we'll take it."

Overall, despite the small firms working across different operational contexts, such an experience indicates an important role of the owner-manager and their flexibility in perceiving alternative routes of decision making and action taking in seemingly shaping the extent to which circumstances are seen as materially fixed and limited. This reinforces the notion that an ownermanager's resilience can have a direct role in small firm performance and a particular pathway to that relationship, i.e. through their adaptability.

Specifically, these findings articulate how the ability of a small firm owner-manager to flexibly adapt to support organisational development and growth varied across the respondents, with some of the respondents apparently discounting viable ways forward. In those instances, it appears that the lack of adaptability could be seen as self-imposed and counter to the potential development or growth of the small firm and, although the capacity to conceptualise options was evident, other situation factors were seen as restrictive and even prohibitive in pursuing these opportunities. Here, it was apparent that the lack of the of owner-manager adaptability - a resource for resilience - is a significant factor in some cases for owner-managers, and within the strategic context of firm choices, that this may be considered as detrimental in dealing with the manifold challenges presented to small firms. Conversely, it could be argued that adaptability, when experienced as being more abundant, is likely to facilitate greater strategic choice for the small firm within which the owner-manager operates, hence increasing the likelihood of organisational development and growth.

Despite all of the small firms being ongoing viable concerns, the dominance of the owner-manager in decision making and action taking in the small firm indicated that they are often critical to the strategic direction and development of that firm. As such, limitations related to the preparedness for change and their impact upon organisational development and growth for some organisations within this study are significant. In particular, such evidence supports the need to develop and extend owner-manager framing capabilities (in decision making and problem 
solving) and related cognitive factors to enable them to consider a wider range of options for strategic decision making and action taking (Osiyevsky and Dewald, 2015).

\section{Owner-manager social support}

All of the owner-managers in the study made reference to the importance of others in relation to the small firm's business operations (see appendix 2 for an overview of the reported networks and contacts). Their points of reference varied greatly and could be categorised by their positioning as business-oriented or relationship-oriented, and differentiated by the relative focus on the operational and technical aspects of running the small firm - versus - the emotional aspects of the self and how they relate to close relations who provide emotional support and advice without the detailed context of the day to day operations of the business. In some instances, owner-managers in family owned and run businesses did not have a clear separation between family- and nonfamilial colleagues, which may have potentially generated a differing dynamic.

In addition, it was evident that although the owner-managers referred to some colleagues in their network as friends, these personal friends did not appear to feature significantly in the data. The reasons for this are not necessarily clear but two possible explanations include (1) that the owner-manager's friends who are not close to the small firm might provide an escape from the pressures of the operation, and therefore are not confided in, and/or (2) that the commitment of owner-managers to the small firm precludes them from more extensive relationships away from firm operations and as such friend networks feature less significantly in the experience of running a small firm. In either case, such roles suggest that friends may have a more indirect or ambiguous role in providing social support to the owner-manager than as conceptualised in this study.

The data do suggest, however, that whilst the structure and organisational arrangement of the small firms varied in the sample, all but one owner-manager (who appeared to be relatively isolated in their role) articulated the strategic benefits from their interactions with others. For example, one owner-manager in small firm $\mathrm{C} 9$ discussed their approach to meetings:

"Well we have, we have obviously lots informal ones and then we occasionally have a formal one... sometimes you ask them [the staff] a question and they'll say 'well I don't know what you're bothering to ask me for because you're going to make the decision anyway'... They don't appreciate that I do like to hear what they have to say even if I don't go along with it all of the time."

Here, whilst the owner-manager recognised the differences in power relationships and personal relationships, the act of consultation was valued and contributed to their assuredness in the critical decisions being made. Such interactions might be understood as helping to mitigate the potential feelings of isolation in being 'the boss', and help to contribute a stronger social network within the workplace and sense of 'family' within the small firm environment. In addition, the social support is a potential contributory factor to effective knowledge management, improving the quality of decision outcomes, even within very informal approaches (Manning, 2010).

This approach contrasted to a more informal discursive context in small firm C8, where the owner-manager had a single main confidante within the organisation, supported by the referral of ideas across the workforce, generally to test and explore acceptance as a precursor to implementation. Although the resulting social network was comparatively more limited than the other approach in exposing to difference perspectives, it was seemingly supported by a single highly trusted and supportive individual relationship. This owner-manager explained:

"[name] and I go up and have a sandwich and a cup of tea and we talk about them because I tend to get tunnel vision and then when I've talked about them with [name] we 
have a, I go round and I talk to everybody else that's involved with it and generally we have a big sort of discussion and then I make autocratic decision \{laughs\}."

In small firm C7, the owner-manager adopted a more structured approach and would meet with external parties (referred to as 'mentors') in order to discuss business matters. In its third year of trading, small firm C7 was the youngest of the firms in the study, and as such was apparently using the external network resource to advise and reflect upon their decision making, potentially in light of their perceived limited experience. The owner-manager here had taken an intentionally planned approach to establishing an expert advisory network from personally known contacts. Despite a number of significant challenges within a turbulent start-up environment, the owner-manager was aware that this network had been effective in helping them to reflect and make well-considered decisions which were critical to the long-term direction of the organisation. They recognised that such a positive experience of utilising these personal in such ways had built a high level of trust through which open dialogue could be accessed in a responsive and flexible manner.

For the small firms with a more formal family interest (for example as shareholders), there was a recognition that the owner-managers had an obligation to discuss the matters relating to the organisation with familial networks. However, it was not always the case that this was conducted in a supportive manner and it was evident that family tensions could have a negative effect upon the focus and motivation of the owner-manager towards the business and their respective abilities to respond to challenges. This was especially the case in relation to family 'infighting' which was seen as being detracting from strategy processes, organisational development and growth. In an extreme case an owner-manager in small firm C3 described how their father, when employed in the firm, provided open, advisory and constructive advice which helped strategic decision making in times of need - and - how these exchanges became relatively guarded and closed when the father left the small firm to set up a direct competitor organisation. Although extreme, this scenario illustrates how the social support which can act as a resource for resilience in a small firm can have an evolving dynamic and character even with respect to the more stable aspects to familial ties.

Overall, the data characterise the social networks of small firm owner-managers as complex and varied with the dynamic and micro-politics of inner firm characters and family interactions entwined with business discussions and non-business matters. Indeed, the data suggest that such social support networks are both formal and informal, and both seem to have a 'mobilising' function (Wall 2016) within small firms which is not only beneficial to the technical aspects of running the small firm, but also the emotional and relational aspects, such as assuredness and emotional support. At the same time, although the data suggest that social support networks were important for all of the small firm owner-managers, networks which include specific reference points for business advice (e.g. external peers or mentors) appear to be more instrumental in focusing owner-managers towards more direct business-oriented processes and outcomes and less emotional or relational activities and issues. Similarly, the data suggest that without a more significant or formal attachment to the small firm, wider social networks may not have a clear or direct role in shaping the resources for resilience of the owner-manager - or more precisely - the owner-manager may not be aware of or be able to articulate the significance of the firm-detached relationships. 
Within the methodological parameters of this study, it is difficult to measure confidence in absolute terms, but there are indicators apparent in the data which reflect small firm ownermanagers' preparedness to innovate and their certainty or optimism in achieving the outcomes related to their decision making or action taking. The rich and longitudinal context of this study has demonstrated across multiple interactions that although the owner-manager's sense of confidence was generally apparent, the focus of it varied across the owner-managers. For example, owner-manager in small firm C6 displayed a real and strong sense of self-belief in their business acumen, and in regard to their competitors, they described their position as follows:

"I want them to be shown for what they are, crap.

I want people to use us as a benchmark for how it's done."

Such a confidence in stance was reflected in their strategic decision making and action taking, whereby they chose to directly compete with competing organisations. In some cases, this involved undertaking acquisitions and mergers with an expressed certainly in being able to turn around any issues with the acquired organisation, or through investment in the resources of the organisation with a strong conviction in the return of such investments. This opportunistic tendency was also exhibited by an owner-manager in small firm C2, a firm exhibiting strong growth characteristics, who referred to an acquisition and merger that involved growth into another geographical market. The owner-manager described it as follows:

"We've bought a company out in Scotland... because I wanted to get my growth so I thought if I'm not going to get any growth out of [place] I need to get it elsewhere."

Here, high self-efficacy and self-belief seemed to be more apparent in the small firms who were seemingly more ambitious in terms of their objectives, for example, where their ownermanagers displayed a strong personal capacity to deal with the challenges that such ambitions and change may bring. This data echoes Baron et al's (2016) findings which suggest these dynamics are prevalent particularly in start-up organisations, but extends it to the more established small firm beyond start-up.

Other respondents were far more cautious about strategic decision making and action taking. For example, owner-manager from small firm $\mathrm{C} 1$ had experienced several business setbacks including market 'hardening', increasing competition, and increasingly powerful customers (based on scale) being able to negotiate less advantageous terms. Such circumstances had seemingly depressed the small firm's revenues and resulting profitability on occasion, apparently shaping the owner-manager's view as to the possible opportunities for development, and manifested as representing what may have been considered as increasing cautiousness or prudence. Here, within a context of frustrated growth and changing markets the owner-manager had decided not to shift focus, despite their recognition of possible strategic development and growth opportunities:

"We're happy in the sector we're in, we're in our comfort zone, we know what we're doing. That's where we're looking to go, we're not looking to go into something we have absolutely no experience of." 
Overall, the data suggest that the notion of confidence is linked to the willingness to adapt and he likelihood of considering alternative opportunities and courses of strategic options such as diversification. In the context of considering the current scope of operations, it also indicated an assuredness of business approach and perceived self-efficacy in dealing with issues through that stance. Alternatively, greater confidence seemingly led to a propensity to take opportunities as they arise, and when the outcomes had been deemed as being successful, further opportunities were then taken. This apparent virtuous, mutually reinforcing cycle indicates the self-reinforcing nature of confidence and how it can develop over time. Conversely, the small owners who demonstrated relatively lower levels of confidence tended to take strategic decisions and action which maintained the stability of their firm operations, even against a backdrop of increasingly challenging environmental conditions.

\section{Owner-manager purposefulness}

With the individual owner-manager and organisation so closely entwined, the objectives of the individual can impinge heavily on the outcomes for the organisation in terms of drive and direction. The data from this study has illustrated that the personal objectives of the respondents varied greatly, and each had a specific personal position regarding lifestyle, life-transition, and fundamentally the purpose of the business in providing for their future. These views run counter to the corporate entity growth and profitability position and recognises the position of small firms as numerous and potentially growth limited or indifferent as entities (appendix 2 summarises their feelings with regard to this).

The owner-manager in small firm C6 perhaps represented the closest (espoused) interest in profit maximisation, wishing to consolidate their position (after achieving a buy-out from the other shareholder) and improve profitability. Here, an upsetting memory of their father dying "penniless", appeared to be a powerful driver in relation to purpose and values (profit and growth), mobilising their efforts and in turn the action of the organisation (Sullivan-Taylor and Branicki, 2011). In contrast, other owner-managers referred to preparing for retirement (and as such securing financial stability), and transitioning from work into different lifestyle choices. This may not be surprising as the sample of owner-managers in this study were aged 45-60 who may arguably have a different viewpoint than a younger group.

Yet there was also evidence of the evolving and dynamic nature of purpose and values over time. For example, an owner-manager in small firm C5 had described how at one point they were driven by extreme dedication to long hours and intense pressure, but this had changed after a life-threatening and life-changing incident. After the incident, their position had shifted towards an improved lifestyle choice which involved spending more quality time with their family. In turn, this was seemingly reflecting in the small firm focusing on business survival without significant aspirations of growth or significantly improved profitability. This owner-manager described how they had purposively - as a result of an externally imposed set of personal circumstances - transited to a 'muddling-through' position (ibid) and had become more averse to tackling more ambitious projects. As such, the owner-manager's personal purposefulness was seemingly intrinsically linked to the strategic drive and direction of the organisation, and directly shaped the strategic stances employed in organisational decision making and taking. 


\section{Discussion}

The paper attempted to explore the 'realities' of small firm owner-managers in relation to their personal resources for resilience, underpinned by a framework developed from the literature. As a framework, it acted as an overarching analytical device to interpret the additional complexities and nuances of the experiences of owner-managers within the context of the small firm. The methodological stance adopted acknowledged that within this complexity, it is challenging to capture and attribute cause-effect relationships, as they are multi-faceted, evolving, and potentially transient. However, it also asserts that when in depth, longitudinal qualitative data are abductively considered within a broader context, it is possible to articulate plausible interpretations and representations of the experiences of owner-managers operating within their respective contexts. That is, whilst objective measurement of the personal resources for resilience is likely to remain elusive, characterisation which elucidates more granular and particular understandings of more generalised theory, is a more reasonable outcome. The implications that arise from this position indicate that advocating actions for the development of the ownermanager's personal resources of resilience, provide a platform from which to improve the ownermanager's own resilience as well as the organisational resilience of the small firm.

This study examined owner-manager's personal resources for resilience within the rich context of the operation of their small firm, specifically through the consideration of: adaptability, social support, confidence and purposefulness. In terms of owner-manager adaptability, there was a variety of responses to disruptive events in the small firms, ranging from (1) a sense of helplessness linked to a belief that the owner-manager worked in an apparently totally-fixed set of circumstances (such as resources and external events) which could not be changed, through to (2) a sense of personal and business level changeability, agility and flexibility supported and perhaps inseparable from a sense of confidence and belief in own capabilities and the business offer. The diversity of response between these two extremes, however, sit in contrast to previous empirical work, in two ways. First, whereas previous research has indicated that small firm owner-managers consistently raise issues in relation to problem solving because of lack of resources (Sullivan-Taylor and Branicki, 2011), this research indicates this is much more varied in practice, and some may not even perceive an event as a disruption. Second, whereas previous research has suggested that framing in problem solving may well lead to adaptive responses (Osiyevskyy and Dewald, 2015), two extreme responses provide a more precise exemplification of how framing can promote certain adaptive or fixed mindsets. For example, the more adaptive mindset was encapsulated by the owner-manager's metaphor of being on (but not necessarily steering) a ship being taken by the tides, and being surprised to find a lighthouse, that is, an unexpected opportunity.

In terms of owner-managers social support, this research found a wide diversity of relationships across different organisational structures, and weak as well as strong ties inside and outside the organisation. Some of these relationships were temporal in nature, for example, where the owner-manager collated teams together to support their own decision making in technical or even emotional dimensions. Again, the findings are in contrast to earlier research which demonstrates an emphasis on supply, infrastructure, and inter-organisational dependence (Sullivan-Taylor and Branicki, 2011). In addition, although the findings resonate with the protective and mobilising role of strong and weak social networks in disruptive moments (Chiesi, 2014; Yilmaz Borekci et al, 2015; Yang and Danes 2015; Bernard and Barbosa, 2016), it does highlight an aspect of social support which has not yet been explore extensively, that is, the discursive nature of how social support is generated. The findings illustrate that some ownermanagers adopt discursive tactics in their strategy development and realization processes. Although such processes may have technical skill input, it also seems that their discursive tactics also aided the owner-manager on an emotional level, perhaps also linking to the development of confidence in own and others' actions and decision pathways. Indeed, such discursive tactics 
have recently been recognised as important in learning and change processes in organisations (MacIntosh et al, 2017; Wall et al 2017a).

Owner-manager responses in relation to confidence also varied, ranging from a strong belief in self and own business, for example, of own business standing in relation to competitors, through to a cautious or prudent focus within comfort zones. However, the expression of confidence was not as pronounced or extreme as found in other studies (e.g. Hayek, 2012; Baron et al, 2016), but it did, in contrast, find close associations between adaptability and confidence: (1) when the owner-manager seemingly described their situation as fixed and unmoveable, there was a sense of helplessness, and their confidence was relatively more cautious and based within their comfort zone, and (2) when the owner-manager perceived their situation as moving and needing adaptivity, they seemed to have a relatively more positive sense of optimism and hope (Bernard and Barbosa, 2016), which seemed to prompt/afford a more ambitious and larger scale strategic direction for growth in the face of challenges. Although the causalities between optimism, hope and resilience are still debated (Quoidbach et al 2015), they do seem to frame strategy development and realisation for the owner-managers and the decisions they make over time.

In terms of purposefulness, owner-managers' sense of purpose and meaning was framed and driven largely by a future state of lifestyle which was likely to impact some element of sustainability for the family, and not typically in terms of profit or monetary outcomes. In addition, such purpose justified extreme dedication to long hours and intense pressure, and particularly in relation to an extreme event experienced earlier in life. These findings are in contrast to earlier work (Sullivan-Taylor and Branicki, 2011), where owner-managers generally reported the difficulties of prioritising actions and limited resources in times of challenge or disruption. However, this finding also illustrates and documents how owner-managers make sense of purposefulness. The findings demonstrate how the owner-managers in this study were driven by a form of necessity (bound in the present now) for a desired level of agency (bound in some future state). By implication, this finding expands the application and relevance of Berkelaar and Buzzanell's (2015) work in describing the purposefulness of owner-managers in small firms, and how it can then shape personal resources for resilience, but also the temporal aspects of purposefulness which are yet unexplored.

Although the four propositions which formed the analytical framework of this study (see Table 1) generated analytic utility in examining the personal resources for resilience, the apparent inter-relatedness of the four areas also emerged from their application within this context. It is therefore important to maintain a meta-perspective of the individual owner-manager's personal resources for resilience in considering the application of this framework. For example, not all owner-managers were found to be positively positioned at all times across all of the resource areas, and even when one area might be considered to be 'weak', the owner-manager was able to demonstrable a capability to be resilience in so much as the owner-manager and their respective organisation endured a disruptive event or challenging situation. This dynamic suggests that deficiencies in one area might be offset by relative strength in other areas, however, it is currently difficult to establish this in the scope of this current study.

Finally, the apparent entanglement of the owner-manager as an individual and the small firm as a larger entity have been outlined. Here, personal confidence, assuredness, the advice sought and received, and ultimately the strategic choices can be closely interconnected, and therefore have a role in the organisational development and growth of a small firm. From this it is reasonable to propose that developing the personal resources for resilience of the owner-manager is likely to influence the organisational development and growth of a small firm. 


\section{Implications}

There are a number of implications deriving from this discussion. First, given the diversity and complex individualised nature of resources for resilience, it is suggested that discursive mechanisms for individualised support (e.g. coaching and mentoring) may offer a more targeted strategy for owner-manager resilience development (Wyrwich et al 2016; Wall et al, 2016; Wall et al, 2017b). Second, and more specifically, individualised support might target adaptability and/or confidence, as these seem to directly influence strategy development and realisation processes, and therefore have direct influences on the longer term gaze of the small firm. Third, such processes may also support sense making in relation to finding purpose and purposefulness, which can act as a positive frame to support and drive own strategy development and realisation in practice, particularly in relation to prioritisation of decision and action taking in the face of challenge. However, whereas there is no consistent evidence of the specific action-taking that owner-managers should make to develop their personal resources for resilience (because of the context sensitivity and dependency of resilience), it is important to create environments where the owner-manager actively generates positive affect (Wall et al 2017c).

\section{Future research and conclusion}

The explosion of interest in resilience has been criticised for creating a complex landscape of theorising (Linnenluecke, 2017) to the extent that it has been linked to some of the challenges in how resilience has been operationalised in empirical work and in practice: (1) that resilience is sometimes not operationally defined, (2) that there may be a variety of inconsistencies between how it is defined and then how it is examined or measured, and (3) that resilience may be defined but then not examined or measured (Roberson et al, 2015). At the same time, and in contrast, the emerging contextual sensitivities or dependencies of resilience seem to afford ample room for ongoing exploration (Ungar, 2011; Ungar and Liebenberg, 2011). It has been argued here that the circumstances of resilience in the context of owner-managers has been underexplored and, because of their unique role within organisational contexts, needs further exploration.

There are a number of further lines of enquiry highlighted by this work. First, as the owner-managers participating in this study we within a particular age (45-60 years of age), it might be possible that certain personal resources for resilience take a more salient profile across the lifespan (Seery et al, 2010). This reflects other life span models of resilience (Bonanno and Mancini, 2011; Bonanno et al 2015), but such models have scope to move from a primary focus on individual differences and trauma to the synthesised manager-in-social-context theorisation (Cooper et al, 2013; Robertson, 2017). Second, as resilience manifests differently across industrial sectors (Kossek and Perrigino, 2016), it might be that owner-managers' resources for resilience present differently according to the specific and more nuanced demands and pressures of industrial sectors.

The third area of further investigation relates to the interface and interrelationships between owner-manager resources for resilience and organisational structure. This is generally more problematic because of the diversity of structures a small firm can adopt, but also because of the contradictory evidence in the literature about organising smaller firms for resilience (Linnenluecke, 2017) - especially as this literature does not reflect the emerging contextual sensitivity and dependency theorisation of resilience (Ungar, 2011; Ungar and Liebenberg, 2011). Exploring the interface and interrelationships between owner-manager resources for resilience and organisational structure will enable more refined and nuanced understandings of the resilience of small firms and therefore generate new practical strategies to support them in practice. 
Finally, it is important to note the point that all of the organisations were ongoing viable entities throughout the study and may therefore be considered to already have a degree of organisational resilience - and indeed - as the owner-managers remained in post throughout the longitudinal span of this research, a degree of personal resilience. As such, given the variability of personal resilience and the purported importance of the owner-manager to the organisation, this reinforces the need for further exploration a more diverse collection of small firm ownermanagers operating in various circumstances (for example, tracking a failing or failed small firm) and contexts (such as industrial sector and cultural context). Together, these lines of inquiry foreground new insights to help support the sustainability of small firms in an ongoing landscape of practice where small firm survival continues to be problematic.

\section{References}

Ali, I., Nagalingam, S., \& Gurd, B. (2017). Building resilience in SMEs of perishable product supply chains: Enablers, barriers and risks. Production Planning \& Control, 28(15), 1236.

Ates, A., \& Bititci, U. (2011). Change process: A key enabler for building resilient SMEs. International Journal of Production Research, 49(18), 5601-5618.

Baron, R. A., Franklin, R. J., \& Hmieleski, K. M. (2016). Why entrepreneurs often experience low, not high, levels of stress: The joint effects of selection and psychological capital. Journal of Management, 42(3), 742-768.

Berkelaar, B. L., \& Buzzanell, P. M. (2015). Bait and switch or double-edged sword? the (sometimes) failed promises of calling. Human Relations, 68(1), 157-178.

Bernard, M., \& Barbosa, S. D. (2016). Resilience and entrepreneurship: A dynamic and biographical approach to the entrepreneurial act.M@N@Gement,19(2),89-121.

Bonanno, G. A., Romero, S. A., \& Klein, S. I. (2015). The temporal elements of psychological resilience: An integrative framework for the study of individuals, families, and communities, Psychological Inquiry, 26(2), 139-169.

Chiesi, A. M. (2014). Interpersonal networking and business resilience: How immigrants in small business face the crisis in Italy. European Sociological Review, 30(4), 457-469.

Cooper, C. L., Flint-Taylor, J., \& Pearn, M. (2013). Building resilience for success: A resource for managers and organizations. New York: Palgrave Macmillan.

Demmer, W. A., Vickery, S. K., \& Calantone, R. (2011). Engendering resilience in small- and medium-sized enterprises (SMEs): A case study of Demmer Corporation. International Journal of Production Research, 49(18), 5395-5413.

Denzin, N and Lincoln, Y (2005), 'The Sage Handbook of Qualitative Research', 3rd Edition, Sage Publications.

Estrada, A. X., Severt, J. B., \& Jiménez-Rodríguez, M. (2016). Elaborating on the conceptual underpinnings of resilience. Industrial and Organizational Psychology, 9(2), 497-502.

Fisher, R., Maritz, A., \& Lobo, A. (2016). Does individual resilience influence entrepreneurial success?. Academy of Entrepreneurship Journal, 22 (2), 39-53.

Fletcher, D. and Sarkar, M. (2013). Psychological resilience: A review and critique of definitions, concepts, and theory. European Psychologist, 18(1), 12-23.

Gunasekaran, A., Rai, B. K., \& Griffin, M. (2011). Resilience and competitiveness of small and medium size enterprises: An empirical research. International Journal of Production Research, 49(18), 5489-5509.

Hayek, M. (2012). Control Beliefs and Positive Psychological Capital: Can Nascent Entrepreneurs Discriminate Between What Can and Cannot be Controlled?. Journal of Management Research, 12(1), 3-13.

Hu, T., Zhang, D. and Wang, J. (2015). A meta-analysis of the trait resilience and mental health, Personality and Individual Differences, 76, 18-27. 
Ismail, H. S., Poolton, J., \& Sharifi, H. (2011). The role of agile strategic capabilities in achieving resilience in manufacturing-based small companies. International Journal of Production Research, 49(18), 5469-5487.

Johnson P and Duberley, J (2000) 'Understanding Management Research ', Sage

Kay, S. A. (2016). Emotion regulation and resilience: Overlooked connections. Industrial and Organizational Psychology, 9(2), 411-415.

Kent, M., Davis, M. C., \& Reich, J. W. (2014). The Resilience Handbook: Approaches to stress and trauma. New York, NY: Routledge.

King, D. D. (2016). The untapped potential in employee resilience: Specific recommendations for research and practice. Industrial and Organizational Psychology, 9(2), 405-411.

Korber, S. and McNaughton, R.B. (2017) Resilience and entrepreneurship: a systematic literature review, International Journal of Entrepreneurial Behavior \& Research, https://doi.org/10.1108/IJEBR-10-2016-0356.

Kossek, E. E., \& Perrigino, M. B. (2016). Resilience: A review using a grounded integrated occupational approach. The Academy of Management Annals, 10(1), 729-797.

Linnenluecke, M. K. (2017). Resilience in business and management research: A review of influential publications and a research agenda. International Journal of Management Reviews, 19(1), 4-30.

MacIntosh, R., Beech, N., Bartunek, J., Mason, K., Cooke, B. and Denyer, D. (2017), "Impact and management research: exploring relationships between temporality, dialogue, reflexivity and praxis", British Journal of Management, Vol. 28 No. 1, pp. 3-13.

Manning, P. (2010) "Explaining and developing social capital for knowledge management purposes", Journal of Knowledge Management, Vol. 14 Issue: 1, pp.83-99.

Morris, M. H., Neumeyer, X., \& Kuratko, D. F. (2015). A portfolio perspective on entrepreneurship and economic development. Small Business Economics, 45(4), 713-728.

Osiyevskyy, O., \& Dewald, J. (2015). Inducements, Impediments, and Immediacy: Exploring the Cognitive Drivers of Small Business Managers' Intentions to Adopt Business Model Change. Journal of Small Business Management, 53(4), 1011-1032.

Quoidbach, J., Mikolajczak, M., \& Gross, J. J. (2015). Positive interventions: An emotion regulation perspective, Psychological Bulletin, 141(3), 655.

Robertson, I. T. (2017). Recognise and react. Occupational Health \& Wellbeing, 69(2), 14.

Robertson, I. T., Cooper, C. L., Sarkar, M., \& Curran, T. (2015) Resilience training in the workplace from 2003 to 2014: A systematic review, Journal of Occupational and Organizational Psychology, 88(3), 533-562.

Rothstein, M. G., McLarnon, M. J. W., \& King, G. (2016). The role of self-regulation in workplace resiliency. Industrial and Organizational Psychology, 9(2), 416-421.

Schwandt, T.A.(1997) Qualitative Inquiry, A Dictionary of Terms, Sage Publications Ltd.

Seery, M. D., Holman, E. A. and Silver, R. C. (2010). Whatever does not kill us: Cumulative lifetime adversity, vulnerability, and resilience, Journal of Personality and Social Psychology, 99(6), 1025-1041.

Storey, D. (1994) Understanding the small business, London: Thomson.

Sullivan-Taylor, B., \& Branicki, L. (2011). Creating resilient SMEs: Why one size might not fit all. International Journal of Production Research, 49(18), 5565-5579.

Thomas, A., Pham, D. T., Francis, M., \& Fisher, R. (2015). Creating resilient and sustainable manufacturing businesses - a conceptual fitness model. International Journal of Production Research, 53(13), 3934-3946.

Ungar, M. (2011). The Social Ecology of Resilience: A Handbook of Theory and Practice, London: Springer.

Ungar, M. and Liebenberg, L. (2011) Assessing Resilience Across Cultures Using Mixed Methods: Construction of the Child and Youth Resilience Measure, Journal of Mixed Methods Research, 5 (2), 126-149. 
Wall, T. (2016) Reviving the Ubuntu spirit in landscapes of practice: evidence from deep within the forest, Journal of Work-Applied Management, Vol. 8 No. 1, pp. 95-98.

Wall, T. (2017), "A manifesto for higher education, skills and work-based learning: through the lens of the manifesto for work", Higher Education, Skills and Work-Based Learning, Vol. 7 No. 3, pp. 304-314.

Wall, T., Bellamy, L., Evans, V. and Hopkins, S. (2017a), Revisiting impact in the context of workplace research: a review and possible directions, Journal of Work Applied Management, Vol. 9 No. 2, pp. 95-109.

Wall, T., Iordanou, I., Hawley, R. and Csigás, Z. (2016), Research Policy and Practice Provocations: Bridging the Gap: Towards Research that Sparks and Connects, The European Mentoring and Coaching Council, Brussels.

Wall, T., Jamieson, M., Csigás, Z. and Kiss, O. (2017b), Research Policy and Practice

Provocations: Coaching Evaluation in Diverse Landscapes of Practice - Towards

Enriching Toolkits and Professional Judgement, The European Mentoring and Coaching Council, Brussels.

Wall, T., Russell, J. and Moore, N. (2017c), Positive emotion in workplace impact: the case of a work-based learning project utilising appreciative inquiry, Journal of Work Applied Management, Vol. 9 No. 2, pp. 129-146.

Wyrwich, M., Stuetzer, M., \& Sternberg, R. (2016). Entrepreneurial role models, fear of failure, and institutional approval of entrepreneurship: A tale of two regions. Small Business Economics, 46(3), 467-492.

Yang, Y., \& Danes, S. M. (2015). Resiliency and resilience process of entrepreneurs in new venture creation. Entrepreneurship Research Journal, 5(1), 1-30.

Yilmaz Borekci, D., Rofcanin, Y., \& Gürbüz, H. (2015). Organisational resilience and relational dynamics in triadic networks: A multiple case analysis. International Journal of Production Research, 53(22), 6839-6867.

Yin, R.K. (2003) Applications of Case Study Research, 2nd Edition, Sage Publications

Appendix 1

Summary of owner-manager role and insights into key relationships

\begin{tabular}{|l|l|l|}
\hline Company & Actor(s) & Role Comment \\
\hline C1 & - Family members & - Father still in position of Chairman, Brother M.D., \\
& - Management team & $\begin{array}{l}\text { Respondent Operations Director. } \\
- \text { Regular management team meetings / daily } \\
\text { interaction }\end{array}$ \\
\hline C2 & - Chairman & $\begin{array}{l}\text { Regular meetings with Chairman (original family } \\
\text { owner) } \\
- \text { Regular management team meetings / daily } \\
\text { interaction, project based }\end{array}$ \\
\hline C3 & - Management team \\
& - Managing Director & $\begin{array}{l}\text { Oather } \\
\text { now Director of large competitor) } \\
- \text { Regular management team meetings, monthly and } \\
\text { quarterly review } \\
- \text { Regular reporting to the board }\end{array}$ \\
\hline C4 & - Non-exec Directors \\
& - Family members & $\begin{array}{l}\text { - Father M.D., Uncle Technical Director, transferring } \\
\text { to Son as M.D., respondent F.D. } \\
- \text { Regular management team meetings / daily }\end{array}$ \\
\hline
\end{tabular}




\begin{tabular}{|c|c|c|}
\hline & & interaction \\
\hline $\mathrm{C} 5$ & - M.D & $\begin{array}{l}\text { - Undertakes majority of management tasks and } \\
\text { dominant in decision making. Occasional discussions } \\
\text { with spouse } \\
\text { - Daily interaction with other employees }\end{array}$ \\
\hline C6 & $\begin{array}{l}\text { - M.D. } \\
\text { - Management team }\end{array}$ & $\begin{array}{l}\text { - } 100 \% \text { owned } \\
\text { - Regular management team meetings / daily } \\
\text { interaction }\end{array}$ \\
\hline C7 & $\begin{array}{l}\text { - Chairman } \\
\text { - Partners } \\
\text { - General manager } \\
\text { - Mentors }\end{array}$ & $\begin{array}{l}\text { - Acting operationally as M.D. } \\
\text { - Regular meetings with investors } \\
\text { - Appointed to run operations, dismissed } \\
\text { - Advice provided to Chairman by two outside parties } \\
\text { through ad hoc meetings / discussions }\end{array}$ \\
\hline C8 & $\begin{array}{l}\text { - M.D. } \\
\text { - Managers } \\
\text { - Consultants }\end{array}$ & $\begin{array}{l}\text { - Daughter of Chairman, who now has little practical } \\
\text { input (similarly other family members input limited) } \\
\text { - One key member of team used as key confidante, } \\
\text { others consulted to lesser extent. } \\
\text { - Used to advise on process development, training, } \\
\text { health and safety, plant investment primarily }\end{array}$ \\
\hline C9 & $\begin{array}{l}\text { - Owner } \\
\text { - Family }\end{array}$ & $\begin{array}{l}\text { - Makes all key decisions } \\
\text { - Mother } 10 \% \text { shareholder (not active in business), } \\
\text { wife employee (noted as task based input only) }\end{array}$ \\
\hline
\end{tabular}

Appendix 2

Summary of owner-manager personal objectives

\begin{tabular}{|l|l|}
\hline Company & Personal objectives \\
\hline C1 & Collective family objective to invest for future (retirement) benefit \\
\hline C2 & $\begin{array}{l}\text { Shift from growth/ profit towards a more enjoyable lifestyle (post impact } \\
\text { event) late in the study }\end{array}$ \\
\hline C3 & Moving towards retirement \\
\hline C4 & Family ownership transition \\
\hline C5 & Company survival and shift to improved lifestyle (post impact event) \\
\hline C6 & Secure personal position, improve profitability \\
\hline C7 & Create and sustain company, move toward retirement \\
\hline C8 & Consolidate prior to retirement \\
\hline C9 & Provide for family, balance with lifestyle \\
\hline
\end{tabular}

